\title{
Primary stroke in a woman with sickle cell anemia responsive to hydroxyurea therapy.
}

\author{
Samir K. Ballas \\ Thomas Jefferson University \\ Ubaldo E. Martinez-Outshoorn \\ Thomas Jefferson University \\ Michael P. Savage \\ Jefferson Medical College
}

Follow this and additional works at: https://jdc.jefferson.edu/cardeza_foundation

Part of the Cardiology Commons

Let us know how access to this document benefits you

\section{Recommended Citation}

Ballas, Samir K.; Martinez-Outshoorn, Ubaldo E.; and Savage, Michael P., "Primary stroke in a woman with sickle cell anemia responsive to hydroxyurea therapy." (2014). Cardeza Foundation for Hematologic Research. Paper 28.

https://jdc.jefferson.edu/cardeza_foundation/28

This Article is brought to you for free and open access by the Jefferson Digital Commons. The Jefferson Digital Commons is a service of Thomas Jefferson University's Center for Teaching and Learning (CTL). The Commons is a showcase for Jefferson books and journals, peer-reviewed scholarly publications, unique historical collections from the University archives, and teaching tools. The Jefferson Digital Commons allows researchers and interested readers anywhere in the world to learn about and keep up to date with Jefferson scholarship. This article has been accepted for inclusion in Cardeza Foundation for Hematologic Research by an authorized administrator of the Jefferson Digital Commons. For more information, please contact: JeffersonDigitalCommons@jefferson.edu. 


\title{
Primary Stroke In A Woman With Sickle Cell Anemia Responsive To Hydroxyurea
}

\author{
Samir K. Ballas ${ }^{1}$, Ubaldo Martinez ${ }^{1}$, Michael Savage ${ }^{2}$ \\ ${ }^{1}$ Cardeza Foundation for hematologic Research, Department of Medicine, Jefferson medical \\ college, Thomas Jefferson University, Philadelphia, PA \\ ${ }^{2}$ Division of Cardiology, Department of Medicine, Jefferson medical college, Thomas Jefferson \\ University, Philadelphia, PA
}

Correspondence:

Samir K. Ballas MD FACP

Cardeza Foundation for Hematologic Research

1020 Locust Street

Philadelphia, PA 19107 USA

Phone: 856-795-6380

Fax: 856-745-0809

E-mail: $\underline{\text { samir.ballas@jefferson.edu }}$

Running head: Stroke in a patient with SS responsive to hydroxyurea

Word count: 1000

The authors have no conflict of interest

Supported in part by the Sickle Cell Program of the Commonwealth of Pennsylvania for the Philadelphia Region 


\begin{abstract}
The most common cause of stroke in children with sickle cell anemia is infarction due to ischemia. In adults, however, stroke is most commonly hemorrhagic in nature. Other causes of stroke in patients with sickle cell disease are very rare. In this short communication we describe a woman with sickle cell anemia responsive to therapy with hydroxyurea who had primary stroke due to paradoxical embolization caused by a large atrial septal defect. Successful management of the stroke included surgical closure of the defect with trans-esophageal echocardiographic guidance. To the best of our knowledge this is the first patient with sickle cell anemia and stroke due to congenital heart disease that did not require open heart surgery for successful management.
\end{abstract}

Key words: sickle cell anemia, stroke, primary stroke, atrial septal defect, patent foramen ovale, paradoxical embolization 


\section{Introduction}

Stroke is a major complication of sickle cell anemia (SS) in children. Its incidence is about $10 \%$ in children with SS less than 10 years of age [1]. Moreover, incidence of silent stroke detected by magnetic resonance imaging (MRI) could be as high as 35\% [2]. Pathophysiologically, these strokes are most often infarctive in nature secondary to cerebrovascular occlusion. Stroke due to SS in adults is less common and is usually due to hemorrhage [1]. Risk factors for recurrent stroke in SS include acute chest syndrome, severe anemia, cerebral vasculopathy, previous stroke and transcranial Doppler ultrasound velocity $>200 \mathrm{~cm} / \mathrm{sec}$ [3]. Other rare causes of recurrent stroke in patients without SS include paradoxical embolization due to patent foramen ovale [4]. In addition, co-existent hyperviscosity or thrombophilia with patent foramen ovale increase the risk of stroke. This scenario was reported in a child with SS and patent foramen ovale [5]. In this communication we describe an adult woman with SS and stroke secondary to paradoxical embolization due to atrial septal defect.

\section{Case Report}

A 42-year-old woman with SS has been followed in our adult sickle cell program for 25 years. Complications of her disease included acute chest syndrome, avascular necrosis of hip joints, mitral valve prolapse, migraine headaches and frequent vaso-occlusive crises (VOC). She was enrolled in the multicenter study of hydroxyurea (MSH) when she was 21 years old and has been on $2500 \mathrm{mg}$ of hydroxyurea (HU) per day since then. She had an excellent response to HU with no recurrent episodes of acute chest syndrome and infrequent need for blood transfusion. After starting HU the frequency of VOC requiring hospital admissions decreased from one admission 
every 1 to 2 months to less than one admission per year except when HU was discontinued due to pregnancy. Her hematologic parameters before and after HU are shown in Table 1.

At the age of 35 years she presented to the emergency room two days after developing abrupt bilateral blurry vision, left facial numbness and weakness of her left leg. Physical exam was remarkable for left lower extremity weakness which was more pronounced proximally. Vital signs were normal. All cranial nerves were intact and there was normal sensation bilaterally. Computed tomography (CT) scan of the brain showed three foci of hypodensity and magnetic resonance imaging (MRI) of the brain showed increased signal on T2, FLAIR and diffusion weighted images within the fronto-parietal deep white matter consistent with infarction in the border zone of the middle cerebral artery (MCA)-anterior cerebral artery (ACA). Magnetic resonance angiography (MRA) of the intra-cerebral and extra-cerebral vessels demonstrated focal narrowing of the right MCA at the trifurcation suggesting an embolic cause. Common causes of ischemic stroke including hypertension, diabetes, atrial fibrillation, renal disease and hyperlipidemia were ruled out with routine studies. Her hemoglobin electrophoresis after admission but before blood exchange transfusion showed $\mathrm{HbS}$ of $55 \%$ and $\mathrm{HbF}$ of $45 \%$. Transthoracic Doppler echocardiography showed minimal mitral, aortic and tricuspid valves regurgitation with tricuspid regurgitant velocity $(\mathrm{TRV})<2.0 \mathrm{~m} / \mathrm{second}$ (normal $<2.5 \mathrm{~m} / \mathrm{second}$ ). She underwent exchange transfusion 2 days after admission and was started on chronic blood exchange transfusions with the assumption that she had ischemic stroke due to SS. Follow-up transesophageal echocardiography after discharge from the hospital showed a secundum atrial septal defect with a defect size of $1.8 \mathrm{~cm}$. Right heart catheterization was performed and the pulmonary flow to systemic flow (Qp/Qs) was 1.7:1 with a mean pulmonary artery pressure of $21 \mathrm{~mm} \mathrm{Hg}$. An Amplatzer atrial septal defect (ASD) closure device was 
deployed with transesophageal echocardiographic guidance with successful closure of the defect. At the patient's request exchange red cell transfusions were discontinued. The patient continued treatment with HU and aspirin. Repeat MRI of the brain after repair of the atrial septal defect showed no acute infarction; there were discrete areas of encephalomalacia and gliosis in the deep white matter of the frontal lobe corresponding to the areas of infarction identified previously. To date, seven years after percutaneous repair of the atrial septal defect she has had no strokes.

\section{Discussion}

The most common cause of stroke in patients with SS is cerebral infarction in children and hemorrhage in adults. The incidence of stroke in adult patients with SS, however, is not well known and more studies are needed in this population [6] . Moreover, patients with SS are prone to other causes of stroke such as cerebral infections, hyperlipidemia, renal disease, congenital heart disease and hyperviscosity [6]. The role of HU in preventing or causing stroke is controversial. Grace et al reported resolution of cerebral artery stenosis in a child with SS treated with HU [7]. On the other hand, Sidani et al reported stroke in a patient with SS on HU and hyperviscosity due to high $\mathrm{Hb}$ level after HU therapy [8]. In addition, the SWITCH study was terminated early because of the increase in secondary stroke with HU [9]. Stroke due to paradoxical embolism associated with congenital heart defect has been reported in patients with SS sporadically. Dowling et al described an 11 year-old girl with recurrent bilateral, strokes associated with patent foramen ovale, antiphospholipid antibodies and increased levels of factor VIII and lipoprotein [5]. A combination of pulmonary arterial hypertension (PAH) and patent foramen ovale may cause paradoxical embolization and stroke. However, stroke has been reported in patients with patent foramen ovale in the presence or absence of PAH [10, 11] which 
is best defined by right heart catheterization (RHC) showing a mean pulmonary artery pressure $\geq$ $25 \mathrm{~mm} \mathrm{Hg} \mathrm{[12].} \mathrm{Our} \mathrm{patient} \mathrm{had} \mathrm{a} \mathrm{mean} \mathrm{pulmonary} \mathrm{artery} \mathrm{pressure} \mathrm{of} 21 \mathrm{~mm} \mathrm{Hg}$ by RHC thus ruling out significant pulmonary hypertension. Moreover, atrial septal defect without stroke was reported in a child with SS associated with successful closure of the defect with open heart surgery [13].To the best of our knowledge , our patient seems to be the first patient with SS and stroke due to paradoxical embolism secondary to atrial septal defect that did not require open heart surgery for successful management. 


\section{References}

1. Ohene-Frempong, K., et al., Cerebrovascular accidents in sickle cell disease: rates and risk factors. Blood, 1998. 91(1): p. 288-94.

2. Steen, R.G., et al., Brain imaging findings in pediatric patients with sickle cell disease. Radiology, 2003. 228(1): p. 216-25.

3. Quinn, C.T. and S.T. Miller, Risk factors and prediction of outcomes in children and adolescents who have sickle cell anemia. Hematol Oncol Clin North Am, 2004. 18(6): p. 1339-54, ix.

4. Benedik, M.P., et al., Patent foramen ovale and unexplained ischemic cerebrovascular events in children. Catheter Cardiovasc Interv, 2007. 70(7): p. 999-1007.

5. Dowling, M.M., et al., Stroke in sickle cell anemia: alternative etiologies. Pediatr Neurol, 2009. 41(2): p. 124-6.

6. Strouse, J.J., et al., The excess burden of stroke in hospitalized adults with sickle cell disease. Am J Hematol, 2009. 84(9): p. 548-52.

7. Grace, R.F., et al., Resolution of cerebral artery stenosis in a child with sickle cell anemia treated with hydroxyurea. Am J Hematol, 2010. 85(2): p. 135-7.

8. Sidani, C.A., et al., Venous sinus thrombosis leading to stroke in a patient with sickle cell disease on hydroxyurea and high hemoglobin levels: treatment with thrombolysis. Am J Hematol, 2008. 83(10): p. 818-20.

9. Ware, R.E., et al., Stroke With Transfusions Changing to Hydroxyurea (SWiTCH): a phase III randomized clinical trial for treatment of children with sickle cell anemia, stroke, and iron overload. Pediatr Blood Cancer, 2011. 57(6): p. 1011-7.

10. Casanovas-Marba, N., et al., Patent Foramen Ovale Causing Severe Hypoxemia Due to Right-toleft Shunting in Patients Without Pulmonary Hypertension. Clinical Suspicion Clues for Diagnosis and Treatment. Rev Esp Cardiol, 2014. 67(4): p. 324-325.

11. Razdan, S., et al., Patent foramen ovale in patients with sickle cell disease and stroke: case presentations and review of the literature. Case Rep Hematol, 2013. 2013: p. 516705.

12. Klings, E.S., et al., An official american thoracic society clinical practice guideline: diagnosis, risk stratification, and management of pulmonary hypertension of sickle cell disease. Am J Respir Crit Care Med, 2014. 189(6): p. 727-40.

13. Gosavi, K.S., et al., Atrial septal defect closure on cardiopulmonary bypass in a sickle cell anemia: role of hydroxyurea and partial exchange transfusion. Ann Card Anaesth, 2010. 13(2): p. 145-7. 
Table 1

Haematological parameters before and after hydroxyurea therapy

\begin{tabular}{|l|c|c|}
\hline \multicolumn{1}{|c|}{ Parameters } & Before Hydroxyurea & After Hydroxyurea $\boldsymbol{\dagger}$ \\
\hline Haemoglobin, $\mathrm{g} / \mathrm{dL}$ & 8.0 & 9.8 \\
\hline Hematocrit, \% & 22.4 & 30.2 \\
\hline Mean corpuscular volume, $\mathrm{Fl}$ & 96 & 132 \\
\hline Mean corpuscular Hb, pg & 34.3 & 39.1 \\
\hline Mean corpuscular Hb concentration & 35.6 & 32.5 \\
\hline Reticulocyte count, \% & 15.4 & 5.3 \\
\hline Reticulocyte count, absolute & $358,820 / \mathrm{uL}$ & $123,500 / \mathrm{uL}$ \\
\hline Fetal Hb, \% & 6.1 & 45 \\
\hline White blood cell count, & $15,800 / \mathrm{uL}$ & $8,500 / \mathrm{uL}$ \\
\hline Platelets, & $537,000 / \mathrm{uL}$ & $452,000 / \mathrm{uL}$ \\
\hline
\end{tabular}

* Baseline data before starting $\mathrm{HU} ; \uparrow$ Data when presented with stroke 